\title{
Treatment in a Geriatric Day Hospital improve individualized outcome measures using Goal Attainment Scaling
}

Paige Moorhouse ${ }^{1,2^{*}}$, Olga Theou', Sherri Fay ${ }^{2}$, Miranda McMillan², Heather Moffatt ${ }^{2}$ and Kenneth Rockwood ${ }^{1,2}$

\begin{abstract}
Background: Evidence regarding outcomes in the Geriatric Day Hospital (GDH) model of care has been largely inconclusive, possibly due to measurement issues. This prospective cohort study aims to determine whether treatment in a GDH could improve individualized outcome measures using goal attainment scaling (GAS) and whether improvements are maintained 6-months post-discharge.
\end{abstract}

Methods: A total of 469 outpatients admitted to a Canadian Geriatric Day Hospital, between December 2008 and June 2011, were included in the analysis ( $81.1 \pm 6.7$ years, 66.3\% females); a smaller cohort of 121 patients received a followup phone call 6 months following discharge. Baseline, discharge and 6 month post-discharge observer-rated measures of mobility, cognition, and function were completed using GAS. Traditional psychometric measures were also captured.

Results: The mean number of goals set was 1.6 (SD 0.8) and patients set goals in the following domains: $88 \%$ mobility or falls reduction; 18\% optimization of home supports; $17 \%$ medication optimization; $12 \%$ cognition; $8 \%$ increasing social engagement; and $5 \%$ optimization of function. Total GAS was the most responsive measure to change with $86 \%$ of patients improving at discharge; mobility goals were the most likely to be achieved. Six-month GAS scores remained significantly higher than GAS scores on admission. Those who had more goals were more likely to improve during GDH admission (OR 1.49, Cl 1.02-2.19) but this association was not seen 6 months after discharge.

Conclusions: This study demonstrated short- and long-term effectiveness of GDH in helping patients achieve individualized outcome measures using GAS.

Keywords: Geriatric day hospital, Goal attainment scaling, Mobility

\section{Background}

Geriatric Day Hospitals (GDH) were developed in the United Kingdom in the late 1950s to help bridge the gap between inpatient and community care for older adults [1]. They aim to foster functional independence (rehabilitative and medical care), and reduce the risk of more serious conditions (preventative care) for communitydwelling older adults through comprehensive assessment and management [2]. GDH teams usually consist of a physician, nurse, social worker, physiotherapist, occupational therapist, psychologist, and dietician. Despite

\footnotetext{
* Correspondence: Paige.Moorhouse@nshealth.ca

'Division of Geriatric Medicine, Dalhousie University, Veterans' Memorial Building, 5955 Veterans memorial Lane, Halifax, Nova Scotia B3H2E1, Canada ${ }^{2}$ Centre for Health Care of the Elderly, Nova Scotia Health Authority, Veterans' Memorial Building, 5955 Veterans memorial Lane, Halifax, Nova Scotia B3H2E1, Canada
}

(c) The Author(s). 2017 Open Access This article is distributed under the terms of the Creative Commons Attribution 4.0 International License (http://creativecommons.org/licenses/by/4.0/), which permits unrestricted use, distribution, and reproduction in any medium, provided you give appropriate credit to the original author(s) and the source, provide a link to the Creative Commons license, and indicate if changes were made. The Creative Commons Public Domain Dedication waiver (http://creativecommons.org/publicdomain/zero/1.0/) applies to the data made available in this article, unless otherwise stated.

evidence that selected multidisciplinary interventions may improve outcomes in some participants, such as decreased risk of falls, the medical literature regarding the long-term outcomes of the day hospital model of care delivery has been largely inconclusive [3-6] in part due to heterogeneity of services provided and outcome measures used $[7,8]$.

The challenge of which tools should be used to demonstrate meaningful outcomes in day hospital patients is well-recognized [7]. Many traditional, standardized psychometric measures have shown responsiveness in day hospital populations; $[5,9]$ however, these measures tend to de-emphasize clinical judgment in favour of maximizing reliability, which may limit validity [8]. Their limitations include: choice of instrument complicating comparisons of effectiveness between programs; responses not being 
analyzed for subgroups of admitted patients; and limiting responsiveness to a specific domain.

In older patients with multiple health issues, individualized outcome measures, such as Goal Attainment Scaling (GAS) may provide a more relevant, scalable, and patient-centered alternative [8]. In contrast to psychometric tests, in which the referent is the population average performance, GAS is a clinometric score in that the referent is the individual. GAS allows for measurement of an unlimited breadth and number of clinically important outcomes, and has demonstrated validity, feasibility, reliability and responsiveness for community dwelling older adults including those undergoing rehabilitation $[8,10,11]$. Also GAS has been endorsed as a measure that can improve patient-centredness by focusing care on what patients want and judging performance, at least in part, by how patients' goals are met $[12,13]$.

Despite its clinical usefulness, data on GAS in day hospital populations is currently limited to one study [3] which showed that $39 \%$ of patients deteriorated after discharge from hospital. Even so, this study did not include patients with known dementia (an increasingly prevalent condition) and did not provide subgroup analyses to investigate what factors could affect changes [3]. We set out to determine whether treatment in a GDH could improve individualized outcome measures using GAS and whether these improvements were maintained 6-months post-discharge. Also we investigated whether achievement of the goals of the patients who attend the $\mathrm{GDH}$ was a function of the goals themselves, the patient's frailty, or other factors.

\section{Methods}

\section{Setting and participants}

This prospective cohort study took place in the GDH at the Nova Scotia Health Authority (Central Zone) in Halifax, Canada. The GDH follows the traditional day hospital model of care and assesses over 200 patients annually. The average length of enrollment is 11 visits (Canadian national average 18) [7] with typically 2 visits/ week. The program runs daily from Monday to Thursday with four patient cohorts attending Monday and Wednesday (mornings or afternoons), or Tuesday and Thursday (mornings or afternoons). Daily census rates average 20 patients. The program is staffed by two separate but overlapping teams each consisting of a physician, a registered nurse, a physical therapist, an occupational therapist and a social worker. Baseline comprehensive multidisciplinary assessments examine cognition, mobility, function, co-morbidities, symptom control and polypharmacy. In addition observer-rated GAS is completed as part of routine care by GDH team members for all patients at admission and discharge.
A total of 490 outpatients were serially admitted to the GDH between December 2008 and June 2011 (Fig. 1). The data of 21 patients were excluded from this study due to abstraction errors $(N=7)$ or missing admission GAS scores $(N=14)$. Of the remaining 469 patients, 25 had no discharge GAS data. Starting September 2010 all admitted patients were asked to receive a follow-up phone call 6 months following discharge $(n=206)$. Consent was obtained from 129 patients (henceforth referred to as the 6 month cohort). Among the 77 who did not consent, 24 declined participation, 14 withdrew from GDH program before consenting, 10 were admitted to hospital or other service before consenting, seven did not end up attending the GDH program, three did not provide a reason, 14 were excluded for other reasons, and for five we missed the opportunity to obtain consent.

Among the 129 who consented, eight did not complete the GDH program and three did not participate in the 6-month follow up phone call leaving a total of 118 patients included in the 6-months follow up analyses (Fig. 1). Follow up GAS data were obtained by a research nurse using a standardized and validated telephone interview [3] with either the patient or their caregiver (in cases where the patient was deceased or cognitive impairment was noted during GDH admission). The 6month follow-up period was selected with the objective of allowing enough time to lapse to show change, but not so much time that new health issues may confound the score [3]. Ethics approval for the study was obtained from the Capital Health Research Ethics Board.

\section{Goal Attainment Scaling (GAS)}

GAS is an individualized, observer-rated, outcome measure designed to capture patient-centred treatment effects on a five-point scale [8]. At admission, problem areas specific to each patient were identified by the GDH multidisciplinary team and set as goals. The team aims to assign goals for the patients that are the most pertinent to the patient (i.e. reason for referral or of concern to the patient), measurable and realistic to achieve during the GDH. Typically $1-3$ goals are assigned per patient; for additional areas of concern for the patients, the team does not assign goal levels to these domains but monitors them. The GDH team groups the goals into four general domains (mobility, function, cognition, other). For goals in the "other" domain, the research team reviewed all goals and grouped them by consensus as social, home support, and medication. Therefore for purposes of analyses, the goals set at admission were grouped into six domains including mobility, cognition, falls, medication optimization, home supports and social issues.

The admission status for each goal was captured descriptively and set at "0" on the scale. Plausible outcome levels representing degrees of improvement or worsening 


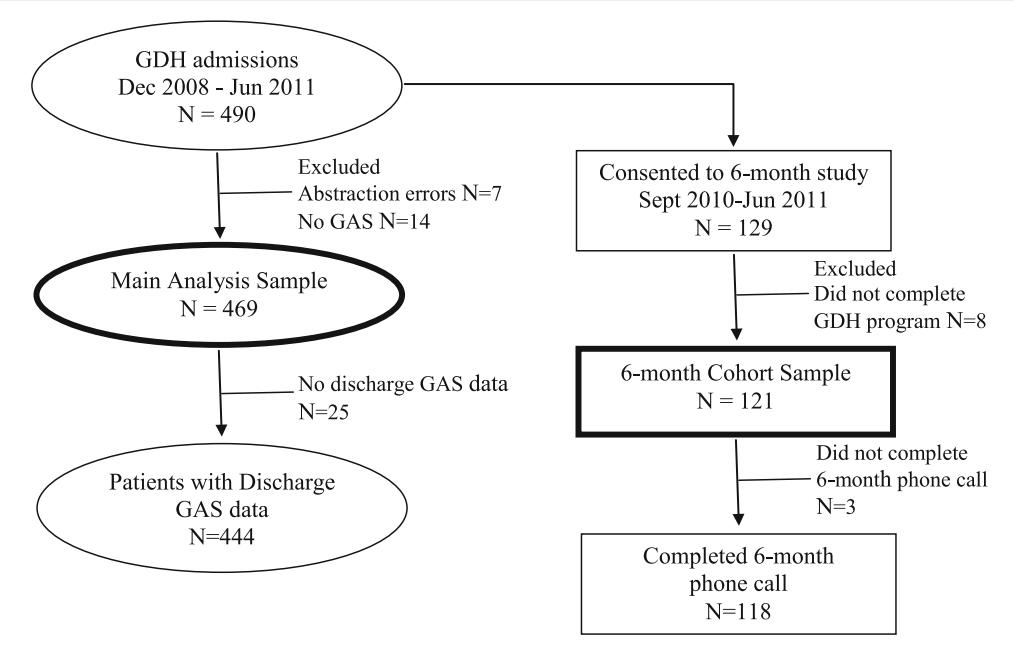

Fig. 1 Patient Flowchart

were documented and designated to one of the four remaining levels of the scale: (i.e., $-2=$ very much worse than baseline; $-1=$ somewhat worse; $+1=$ somewhat better; and $+2=$ very much better). For example, the GDH team set a mobility goal for patient $Y$, who reported having one fall per week and difficulty with stairs (admission status $=0$ ). The desired outcomes for this patient were identified as having less than one fall/week and following the recommendations of the GDH team regarding stairs $(+1$ "somewhat better") and having no further falls and no difficulty with stairs (+2 "much better"). At GDH discharge the goals were reviewed by the GDH team and the level of goal attainment (i.e., the score) was determined by the extent to which the current status conformed to one of the levels defined at admission (no evident change from baseline was scored as 0). During the 6 month follow up telephone interview, the research nurse enquired about the current level of functioning for each original goal and then scored goal attainment in accordance with the scale defined at admission. The research nurse was blinded to the goal attainment scores assigned at discharge.

GAS scores are standardized by a summary formula that adjusts for varying numbers of goals per patient and varying levels of attainment per goal:

$$
\text { GAS }=50+\left\{\left(10 * \sum \mathrm{w}_{\mathrm{i}} \mathrm{x}_{\mathrm{i}}\right) /\left(\left(0.7 * \sum \mathrm{w}_{\mathrm{i}}+0.3 *\left(\sum \mathrm{w}_{\mathrm{i}}\right) 2\right)^{1 / 2}\right)\right\}
$$

where $x_{i}$ is the individual attainment level (between -2 and +2 ) and $w_{i}$ is the weight of the goal (in this study all goals were weighted as 1 ). The formula results in a score of 50 when all goals remain at 0 (as is the case at admission when goals are first set), $<50$ when there is net worsening across goals, and $>50$ when there is net improvement across goals. An overall GAS score (Total
GAS) was calculated for each patient, as well as scores for goals by domain.

\section{Other health measures}

Patients attending the GDH routinely complete a battery of standardized, validated psychometric measures upon admission and discharge (Table 1). The Mini-Mental State Examination (MMSE) [14] is a brief, 20-item instrument that measures orientation to time and place, immediate recall, short-term memory, calculation, language and constructive ability. The maximum obtainable score is 30 and the published minimum detectable change (MDC) is 3 points $[15,16]$. The BERG Balance Scale (BBS) [17] is a 14-item functional measure of balance impairment in ambulatory older individuals, with an MDC of 5-7 points depending on baseline [18]. The Performance Oriented Mobility Assessment (POMA) [19] is a widely-used assessment of mobility, balance and gait in older populations. The maximum score is $28(12$ points for the gait component and 16 points for the balance component) and the MDC is 5 points [20]. The Timed Up and Go (TUG) [21] is an evaluation of transfers and ambulation with an MDC of 4 seconds [22, 23]. The Elderly Mobility Scale (EMS) [23] assesses mobility in 7 dimensions of functional performance including locomotion, balance and key position changes for a total score of 20. Its MDC is 3 points [24]. The Lawton Brody Instrumental Activities of Daily Living scale [25] is a validated assessment of function in older adults with an MDC of 1 point [26].

Frailty at admission was operationalized using the deficit accumulation approach. A frailty index was constructed following a standard methodology [27] by combining 37 measures collected as a part of the standard assessment upon admission to the GDH [(e.g. weight 
Table 1 Outcome measures and their minimum detectable change

\begin{tabular}{|c|c|c|c|c|}
\hline Measure & Description & $\begin{array}{l}\text { On } \\
\text { admission }\end{array}$ & $\begin{array}{l}\text { On } \\
\text { discharge }\end{array}$ & $\begin{array}{l}\text { Minimum detectable } \\
\text { change }\end{array}$ \\
\hline $\begin{array}{l}\text { The Mini Mental Status } \\
\text { Examination (MMSE) }\end{array}$ & 30-point test of cognition & $\checkmark$ & $\checkmark$ & 3 points $[15,16]$ \\
\hline Berg Balance Scale (BBS) & 14-item functional measure of balance impairment & $\checkmark$ & $\checkmark$ & $\begin{array}{l}5-7 \text { points depending } \\
\text { on baseline }[17,18]\end{array}$ \\
\hline $\begin{array}{l}\text { The Performance Oriented } \\
\text { Mobility Assessment (POMA) }\end{array}$ & $\begin{array}{l}\text { Assessment of mobility, balance and gait: } 12 \text { points for the gait } \\
\text { component and } 16 \text { points for the balance component }\end{array}$ & $\checkmark$ & $\checkmark$ & 5 points $[19,20]$ \\
\hline The Timed Up and Go (TUG) & $\begin{array}{l}\text { Evaluation of sequential locomotor tasks including chair transfers } \\
\text { and ambulation with well-established norms }\end{array}$ & $\checkmark$ & $\checkmark$ & 4 seconds [21-23] \\
\hline Elderly Mobility Scale (EMS) & $\begin{array}{l}\text { 20-point multidimensional assessment of mobility in frail elderly } \\
\text { patients }\end{array}$ & $\checkmark$ & $\checkmark$ & 3 points $[23,24]$ \\
\hline Lawton Brody & Validated scale to measure instrumental activities of daily living & $\checkmark$ & $\checkmark$ & 1 point $[25,26]$ \\
\hline Frailty Index & $\begin{array}{l}37 \text { variables describing the proportion of accumulated deficits in } \\
\text { an individual (baseline frailty) }\end{array}$ & $\checkmark$ & & N/A \\
\hline Goal Attainment Scaling (GAS) & Clinometric scale describing changes in patient directed goals & $\checkmark$ & $\checkmark$ & Any change \\
\hline
\end{tabular}

loss, mobility impairment, and osteoporosis). Each of the included variables was coded to represent the presence or the absence of a health problem. A frailty index score, ranging from 0 to 1 , was calculated for each patient by dividing the number of health problems the patient had by 37; if a patient had X missing data then the denominator was adjusted (i.e., 37-X). The characteristics of the frailty index constructed for this study were similar to those from other clinical databases. The frailty index is designed to be used as a continuous measure, however, cut points have been suggested to identify frailty groups: 0 to $\leq .10$ non frail, $>.10$ to $\leq .21$ vulnerable, $>.21$ to $<0.45$, mildly/moderately frail, $\geq 0.45$ severely frail [28].

\section{Statistical Analyses}

Statistical analyses were carried out using IBM SPSS Statistics (version 22) and R Studio (version 0.98.1103). Descriptive statistics and comparisons between groups (e.g., those in the main cohort who were followed up at 6months vs. those who were not and those who improved on GAS vs. those who did not) were carried out with ttests and Chi squared analyses. Changes in psychometric measures (admission to discharge) and GAS (admission, discharge, 6 months follow up) were examined using repeated measures ANOVA. The responsiveness of each measure was compared by calculating the standardized response mean (mean change divided by the standard deviation of the change scores) [29] and the proportion of patients who improved by at least the established MDC values (note that for GAS any improvement is considered clinical significant and was recorded as MDC). We performed univariate logistic regression analyses and one way ANOVAs to determine the relationship between baseline characteristics and improvement on Total GAS at discharge and 6 months.

\section{Results}

The main cohort included 469 sequential patients $(34 \%$ male) with a mean age of $81.1 \pm 6.7$ years (range 62-99) and a mean length of enrollment of $58 \pm 19$ days (Table 2 ). Patients were referred by general practitioners (47\%), geriatricians (33\%), other specialists (10\%), emergency department (6\%) and community sources (4\%). Reasons for referral included falls (59\%), mobility impairment (31\%), Parkinson's disease (3\%), cognitive impairment (2\%), medication/polypharmacy (2\%), and other reasons (3\%). At baseline, participants had mild impairment of cognition, moderate to severe impairment of mobility, and impairment of Instrumental Activities of Daily Living (Table 2). Among the 446 participants with valid frailty scores, 3\% were non frail, 22\% vulnerable, 65\% mildly/ moderately frail, and $10 \%$ severely frail. The mean number of goals set per patient was $1.6 \pm 0.8$. Goals were most commonly set for mobility or falls reduction (88\%), followed by optimization of home supports (18\%), medication optimization (17\%), cognition (12\%), increasing social engagement (8\%), and optimization of function (5\%).

Comparison of discharge scores to admission scores revealed that all measures improved statistically except for the MMSE $(p=0.09)$. Total GAS was the most responsive measure to change with $86 \%$ of patients improving at discharge (Standardized Response Mean 1.62) (Table 3). Only four patients declined in Total GAS at discharge and due to this small number, when examining changes in GAS, these patients were combined with those who remained stable $(N=59)$. Looking at goals by domain, more patients improved on mobility and home support goals (Table 3).

The 121 patients who were followed up 6 months after discharge had lower $(p<0.001)$ frailty index $(0.26 \pm 0.10$ vs. $0.31 \pm 0.12)$ and Lawton Brody scores $(3 \pm 1.9$ vs. $3.9 \pm 2.1)$ at baseline compared to the 348 patients 
Table 2 Baseline characteristics for the main cohort and the 6-month follow-up cohort by GAS-improvement status at discharge and 6 months, respectively

\begin{tabular}{|c|c|c|c|c|c|c|}
\hline \multirow{2}{*}{$\begin{array}{l}\text { Baseline Characteristic } \\
\text { mean (SD) unless } \\
\text { otherwise indicated }\end{array}$} & \multicolumn{3}{|l|}{ Main cohort } & \multicolumn{3}{|c|}{ 6-months follow up cohort } \\
\hline & All & $\begin{array}{l}\text { Improvement on } \\
\text { GAS at discharge }\end{array}$ & $\begin{array}{l}\text { No improvement on } \\
\text { GAS at discharge }\end{array}$ & All & $\begin{array}{l}\text { Improvement on } \\
\text { GAS at } 6 \text { months }\end{array}$ & $\begin{array}{l}\text { No improvement on } \\
\text { GAS at } 6 \text { months }\end{array}$ \\
\hline N & 469 & 381 & 63 & 121 & 99 & 19 \\
\hline Age & $81.1(6.7)$ & $81.2(6.8)$ & 80.7 (6.6) & $80.8(6.7)$ & $80.9(6.7)$ & $79.8(7.0)$ \\
\hline Sex [female n (\%)] & $311(66.3 \%)$ & $251(65.9 \%)$ & $40(63.5 \%)$ & $84(69.4 \%)$ & $70(70.7 \%)$ & $12(63.2 \%)$ \\
\hline Program length (days) & $58.1(19.0)$ & $59(17.6)$ & $54.1(25.2)$ & $60.8(23.8)$ & $61.5(25.8)$ & $55.5(10.8)$ \\
\hline MMSE & $25.6(3.8)$ & $25.7(3.7)$ & $25.4(3.8)$ & $26.1(3.3)$ & $26.1(3.4)$ & $25.5(2.5)$ \\
\hline BBS & $37.3(9.7)$ & $37.7(9.3)$ & $36.1(10.9)$ & $38.2(9.5)$ & $37.8(9.8)$ & $39.3(7.9)$ \\
\hline POMA & $9.6(3.3)$ & $9.7(3.3)$ & $9.3(3.6)$ & $9.9(3.6)$ & $9.7(3.3)$ & $10.1(3.3)$ \\
\hline EMS & $16.1(2.9)$ & $16.2(2.8)$ & $15.9(3.3)$ & $16.5(2.8)$ & $16.4(2.9)$ & $16.5(2.6)$ \\
\hline Lawton Brody & $3.7(2.1)$ & $3.5(2.0)$ & $4.0(2.4)$ & $3.0(1.9)$ & $3.0(1.9)$ & $3.0(1.7)$ \\
\hline TUG & $22.8(11.9)$ & $22.4(10.5)$ & $24.7(18.5)$ & $22.2(10.5)$ & $22.5(10.5)$ & $21.4(10.9)$ \\
\hline Frailty Index & $0.30(0.11)$ & $0.29(0.11)$ & $0.31(0.12)$ & $0.26(0.10)$ & $0.26(0.10)$ & $0.27(0.11)$ \\
\hline GAS, number of goals & $1.64(0.81)$ & $1.67(0.83)$ & $1.44(0.76)^{*}$ & $1.52(0.76)$ & $1.55(0.80)$ & $1.37(0.60)$ \\
\hline
\end{tabular}

*Significantly different than those who improved at discharge $(p=0.04)$

BBS BERG Balance Scale; EMS Elderly Mobility Scale; GAS Goal Attainment Scaling; MMSE, Mini-Mental State Examination; POMA, Performance Oriented Mobility Assessment; TUG Timed Up and Go

who were not followed up; all other baseline characteristics were similar. At discharge those who were followed up 6 months had lower Lawton Brody scores $(3.1 \pm 1.9$ vs. $3.9 \pm 2.0)$ and higher GAS scores (Total $65.3 \pm 7.2$ vs. $61.5 \pm 7.7$; mobility $64.4 \pm 7.2$ vs. $61.0 \pm$ 8.1; cognition $65 \pm 9.3$ vs. $56.7 \pm 6.3$; function $62.9 \pm$ 4.9 vs. $56.3 \pm 5$; medication $68.2 \pm 11.2$ vs. $61.4 \pm 8.4$ ); all other discharge characteristics were similar. Among the 6-month cohort, improvement at 6-months compared to admission remained evident for Total GAS and all GAS domains except cognition and function; the sample size for those domains was less than 10 patients (Table 4).

Using improvement as the outcome, in univariate logistic regression analyses, those who had more goals, were more likely to improve during GDH admission (OR for number of goals 1.49, CI 1.02-2.19, $p=0.04$ ) but these associations were not seen at 6 months after discharge. None of baseline characteristics (i.e., age, sex, frailty index, length of enrollment, and baseline cognitive, functional or mobility psychometric scores) predicted improvement during GDH stay or at 6 months

Table 3 Outcomes, change and responsiveness by health measure between GDH admission and discharge for main cohort

\begin{tabular}{|c|c|c|c|c|c|c|}
\hline Measure & $N$ & Admission mean (SD) & Discharge mean (SD) & Change mean (SD) & $\begin{array}{l}\text { Standardized } \\
\text { Response Mean }\end{array}$ & $\begin{array}{l}\% \text { Achieving } \\
\text { Positive MDC }\end{array}$ \\
\hline MMSE & 371 & $25.6(3.6)$ & $25.9(4.2)$ & $0.32(3.66)$ & 0.09 & $22 \%$ \\
\hline BBS & 399 & $37.7(9.5)$ & $44.3(8.1)^{*}$ & $6.63(6.32)$ & 1.05 & $61 \%$ \\
\hline POMA & 397 & $9.7(3.3)$ & $12.0(2.8)^{*}$ & $2.34(2.75)$ & 0.85 & $20 \%$ \\
\hline EMS & 405 & $16.2(2.9)$ & $17.9(2.9)^{*}$ & $1.68(3.08)$ & 0.55 & $57 \%$ \\
\hline Lawton Brody & 396 & $3.6(2.0)$ & $3.7(2.0)^{*}$ & $0.12(0.75)$ & 0.16 & $6 \%$ \\
\hline TUG & 398 & $22.4(10.8)$ & $18.1(8.0)^{*}$ & $-4.33(7.49)$ & -0.58 & $48 \%$ \\
\hline GAS Total & 444 & 50 & $62.6(7.8)^{*}$ & $12.56(7.76)$ & 1.62 & $86 \%$ \\
\hline GAS Mobility & 412 & 50 & $61.9(8.0)^{*}$ & $11.93(8.03)$ & 1.49 & $82 \%$ \\
\hline GAS Cognition & 56 & 50 & $57.9(7.3)^{*}$ & $7.90(7.33)$ & 1.08 & $64 \%$ \\
\hline GAS Function & 23 & 50 & $58.3(5.8)^{*}$ & $8.26(5.76)$ & 1.43 & $74 \%$ \\
\hline GAS Medication & 78 & 50 & $62.8(9.4)^{*}$ & $12.80(9.38)$ & 1.36 & $79 \%$ \\
\hline GAS Home Supports & 85 & 50 & $58.9(5.2)^{*}$ & $8.86(5.21)$ & 1.70 & $80 \%$ \\
\hline GAS Social & 35 & 50 & $57.7(4.3)^{*}$ & $7.71(4.26)$ & 1.81 & $77 \%$ \\
\hline
\end{tabular}

*Significantly different from admission $(p<0.05)$

BBS BERG Balance Scale; EMS Elderly Mobility Scale; GAS, Goal Attainment Scaling; MDC- minimum detectable change; MMSE, Mini-Mental State Examination; POMA, Performance Oriented Mobility Assessment; TUG Timed Up and Go 
Table 4 GAS change from admission at discharge and 6 months following discharge for the 6-months follow up cohort

\begin{tabular}{|c|c|c|c|c|c|}
\hline \multirow[t]{3}{*}{ Measure } & \multirow[t]{3}{*}{$N$} & \multirow[t]{3}{*}{ Discharge mean (SD) } & \multirow[t]{3}{*}{ 6-months mean (SD) } & \multicolumn{2}{|c|}{$\%$ of patients who improved } \\
\hline & & & & Discharge & 6 months \\
\hline & & & & N (\%) & N (\%) \\
\hline GAS Total & 118 & $65.3(7.3)^{*}$ & $61.4(8.1)^{*} \#$ & $113(96 \%)$ & 99 (84\%) \\
\hline GAS Mobility & 109 & $64.4(7.1)^{*}$ & $61.1(8.1)^{*} \#$ & $103(94 \%)$ & $90(83 \%)$ \\
\hline GAS Cognition & 8 & $65.0(9.3)^{*}$ & $53.8(9.2)$ & $7(88 \%)$ & $5(63 \%)$ \\
\hline GAS Function & 6 & $63.3(5.2)^{*}$ & $56.7(10.3)$ & $6(100 \%)$ & $4(67 \%)$ \\
\hline GAS Medication & 15 & $68.7(11.3)^{*}$ & $58.3(6.4)^{*} \#$ & $13(87 \%)$ & $11(73 \%)$ \\
\hline GAS Home Supports & 17 & $60.0(3.5)^{*}$ & $58.8(6.0)^{*}$ & $16(94 \%)$ & $13(76 \%)$ \\
\hline GAS Social & 8 & $58.8(3.5)^{*}$ & $58.8(6.4)^{*}$ & $7(88 \%)$ & $6(75 \%)$ \\
\hline
\end{tabular}

*Significantly different from admission $(p<0.05)$

\#Significantly different from discharge $(p<0.05)$

GAS, Goal Attainment Scaling

after discharge $(p>0.05)$. Findings were similar when comparing the characteristics of those patients who experienced improvement during GDH stay to those who did not improve during GDH stay (Table 2).

\section{Discussion}

The GDH model provides a solution to locally and nationally identified programmatic needs. On a national level, the importance of outpatient rehabilitative programs for reducing costs and improving outcomes is well recognized [30]. Previous studies examining outcomes in GDH have relied upon numerous psychometric measures [5] or GAS alone [3]. GAS appears to be a responsive measure to change in this population. Our results are consistent with and build upon those of Crilly et al. [3] as this GDH population is larger and includes those with dementia. This study also appears to demonstrate maintenance of benefit from GDH at 6 months post discharge. This is in contrast to the study of Malone et al. [5], which found that gains in mobility or function were not maintained at 3 months in a population with baseline characteristics similar to the current study. It is difficult to know whether the responsiveness of GAS explains the difference in longer term outcomes between these two studies.

Although responsive, GAS cannot be readily used as a means to select optimal candidate patients for the GDH service since none of the patient baseline characteristics predicted response to rehabilitation. Therefore no single baseline measure appears to predict overall GDH performance [31] or longer term maintenance of improvements. While this finding may seem discouraging from a patient selection perspective, it also suggests that adaptive interventions such as the GDH, can effectively serve a wide range of people. Although not an optimal selection tool, the use of GAS could streamline patient assessment on admission and discharge by reducing the number of psychometric measures that are completed for each patient. One of the current criticisms of the use of multiple psychometric measures in rehabilitative programs is that they are time consuming [30]. Second, a streamlined approach to outcome measurement within the GDH may allow front line care workers to spend less time charting outcomes, and more time in direct patient care.

Our study has several important limitations. The patients who were followed up 6 months after discharge had lower frailty and higher functional ability at baseline and higher function and GAS scores at discharge compared to those patients who were not followed up. No comparison groups were added and no measures other than GAS were repeated at 6 months. Also GAS scores at 6 months after discharge were based on patient or (in the case of cognitively impaired patients) caregiver report (vs. GDH care team observations at admission and discharge). On the other hand, patient-centred interventions need to produce changes that patients or caregivers can on average recognize as meaningful [13].

\section{Conclusions}

This study demonstrated short- and long-term effectiveness of GDH in helping patients achieve individualized outcome measures using GAS. The GDH therefore has the potential to help answer the call of our growing population of frail older adults who typically benefit more from a continuum of community care than from the traditional admit-discharge model of our health care system $[3,7]$. Future studies dealing with the cost effectiveness of GDH interventions may benefit from using a GAS outcome measure in order to understand the economic case as it relates to individualized outcomes that matter to patients.

\section{Abbreviations}

BBS: BERG Balance Scale; Cl: Confidence Interval; EMS: Elderly Mobility Scale; GAS: Goal attainment scaling; GDH: Geriatric Day Hospital; MDC: Minimum 
detectable change; MMSE: Mini-Mental State Examination; OR: Odds ratio; POMA: Performance Oriented Mobility Assessment; SD: Standard deviation; TUG: Timed Up and Go

\section{Acknowledgements}

We would like to acknowledge Tracie Fisher's contribution for extracting and cleaning data from the GDH database.

\section{Funding}

This work was supported by the Dalhousie University Internal Medicine Research Fund. Funders played no role in the design, execution, analysis and interpretation of data, or writing of the study.

\section{Availability of data and material}

The datasets during and/or analysed during the current study available from the corresponding author on reasonable request.

\section{Authors' contributions}

PM contributed to the study concept and design, acquisition of data, analysis and interpretation of data, and preparation of manuscript. OT contributed to data analysis, interpretation of data and preparation of manuscript. SF contributed to study design, data collection, interpretation of data, and preparation of manuscript. MM and HM contributed to data analysis. KR contributed to the design and analyses of the study. All authors read and approved the final manuscript.

\section{Competing Interests}

The authors declare that they have no competing interests.

\section{Consent for publication}

Not applicable.

\section{Ethics approval and consent to participate}

Ethics approval for the study was obtained from the Capital Health Research Ethics Board. Consent was obtained from all patients who participated in the 6-month follow up study.

Received: 8 September 2016 Accepted: 10 December 2016 Published online: 07 January 2017

\section{References}

1. Benson D. Measuring outcomes in ambulatory care. Chicago, IL: American Hospital Publishing, Inc; 1992

2. British Geriatric Society. Geriatric Day Hospitals for Older People Best Practice Guide, 2006

3. Crilly RG, Lytwynec S, Kloseck M, et al. Patient outcomes after discharge from a geriatric day hospital. Can J Aging. 2005:24:305-9.

4. Black DA. The Geriatric day hospital. Age Ageing. 2005;34:427-9

5. Malone M, Hill A, Smith G. Three-month follow up of patients discharged from a geriatric day hospital. Age Ageing. 2002;31:471-5.

6. Petermans J, Velghe A, Gillain D, Boman X, Van Den Noortgate N. Geriatric day hospital: what evidence? A systematic review. Geriatr Psychol Neuropsychiatr Vieil. 2011;9(3):295-303.

7. Lewis D, Awad M. Geriatric Day Hospitals in Organization Design for Geriatrics: An evidence-based approach. Prepared for the Regional Geriatrics Programs of Ontario, 2008

8. Rockwood K, Howlett S, Stadnyk K, Carver D, Powell C, Stolee P. Responsiveness of goal attainment scaling in a randomized controlled trial of comprehensive geriatric assessment. J Clin Epidemiol. 2003;56:736-43.

9. Desrosiers J, Hebert R, Payette $H$, et al. Geriatric day hospital: who improves the most? Can J Aging. 2004;23:217-29.

10. Stolee P, Rockwood K, Fox RA, Streiner DL. The use of Goal Attainment Scaling in a geriatric care setting. J Am Geriatr Soc. 1992;40:574-8.

11. Stolee P, Stadnyk K, Myers AM, Rockwood K. An individualized approach to outcome measurement in geriatric rehabilitation. J Gerontol A Biol Sci Med Sci. 1999;54(12):M641-7.

12. Reuben DB, Tinetti ME. Goal-oriented patient care-an alternative health outcomes paradigm. N Engl J Med. 2012;366:777-9.

13. American Geriatrics Society Panel on Person-Centered Care. Person-Centered Care: A definition and essential elements. J Am Geriatr Soc. 2016;64(1):15-8.
14. Folstein M. Folstein Sm McHugh P. "Mini-Mental State". A practical method for grading the cognitive status of patients for the clinician. J Psychiatric Res. 1975;12:189-98.

15. Hensel A, Angermeyer MC, Riedel-Heller SG. Measuring cognitive change in older adults: reliable change indices for the Mini-Mental State Examination. J Neurol Neurosurg Psychiatry. 2007;78(12):1298-303.

16. Doody RS, Massman P, Dunn JK. A method for estimating progression rates in Alzheimer disease. Arch Neurol. 2001;58(3):449-54.

17. Berg K, Wood-Dauphinee S, Williams Jl, Gayton D. Measuring balance in the elderly: preliminary development of an instrument. Physiother Can. 1989:41:304-11.

18. Berg KO, Wood-Dauphinee SL, Williams Jl, Maki BE. Measuring balance in the elderly: validation of an instrument. Can J Public Health 1992b;83 (Suppl 2): S7-11

19. Tinetti ME. Performance-oriented assessment of mobility problems in elderly patients. J Am Geriatr Soc. 1986;34:119-26.

20. Faber MJ, Bosscher RJ, van Wieringen PC. Clinimetric properties of the performance-oriented mobility assessment. Phys Ther. 2006;86:944-54.

21. Podsiadlo D, Richardson S. The timed "Up \& Go": a test of basic functional mobility for frail elderly persons. J Am Geriatr Soc. 1991;39:142-8.

22. Ries JD, Echternach JL, Nof L, Gagnon BM. Test-retest reliability and minimal detectable change scores for the timed "up \& go" test, the six-minute walk test, and gait speed in people with Alzheimer disease. Phys Ther. 2009;89:569-79.

23. Smith R. Validation and Reliability of the Elderly Mobility Scale. Physiotherapy. 1994;80:744-7.

24. de Morton NA, Berlowitz DJ, Keating U. A systematic review of mobility instruments and their measurement properties for older acute medical patients. Health Qual Life Outcomes. 2008;6:44.

25. Lawton MP, Brody EM. Assessment of older people: Self-maintaining and instrumental activities of daily living. Gerontologist. 1969;9:179-86.

26. Graf C. Functional decline in hospitalized older adults. Am J Nurs. 2006; 106(1):58-67.

27. Searle S, Mitnitski A, Gahbauer EA, Gill TM, Rockwood K. A standard procedure for creating frailty index. BMC Geriatr. 2008;30:24.

28. Hoover M, Rotermann M, Sanmartin C, Bernier J. Validation of an index to estimate the prevalence of frailty among community-dwelling seniors. Health Rep. 2013:24(9):10-7.

29. Liang MH, Fossel AH, Larson MG. Comparisons of five health status instruments for orthopedic evaluation. Med Care. 1990;28:632-42.

30. Teasell R, Meyer MJ, Foley N, Salter K, Willems D. Stroke rehabilitation in Canada: a work in progress. Top Stroke Rehabil. 2009;16:11-9.

31. Pereira SR, Chiu W, Turner A, et al. How can we improve targeting of frail elderly patients to a geriatric day-hospital rehabilitation program? BMC Geriatr. 2010:10:82

\section{Submit your next manuscript to BioMed Central and we will help you at every step:}

- We accept pre-submission inquiries

- Our selector tool helps you to find the most relevant journal

- We provide round the clock customer support

- Convenient online submission

- Thorough peer review

- Inclusion in PubMed and all major indexing services

- Maximum visibility for your research

Submit your manuscript at www.biomedcentral.com/submit 